\title{
INTUMESCENCES ON POPLAR LEAVES. III. THE ROLE OF PLANT GROWTH HORMONES IN THEIR PRODUCTION ${ }^{1}$
}

\author{
Carl D. La Rue
}

Is rwo preceding papers the author has discussed the development of the peculiar outgrowths on poplar leaves which are known as intumescences (La Rue, $1933 \mathrm{a}, 1933 \mathrm{~b})$. They have been reported on a number of other species by various authors; and in addition to finding them on Populus grandidentata and Populus tremuloides, the author (La Rue, 1933c) has reported them on Mitchella repens, Eucalyptus coccifera, Eucalyptus cornuta, Hieracium venosum, and Thurberia thespesioides. These outgrowths have been attributed to wind-blown sand, to frost injury, to excessively moist air, etc. In the first of the papers mentioned above ( $\mathrm{La}$ Rue, 1933a) the writer described the morphology and development of the outgrowths on poplar leaves and in the second (La Rue, 1933b) gave a detailed account showing that these abnormal structures were associated with the lowered oxygen tension in the unventilated chambers in which they were produced.

The recent developments in the study of the plant growth hormones (Thimann, 1935; Went, 1935), led the author to suspect that hormones played a part in the growth of intumescences, since these structures on poplar leaves consist entirely of cells which have grown to abnormal size. The present paper is an account of studies of the possible part played by plant growth hormones in the abnormal expansion of the cells of these outgrowths.

Methods AND Materials.-Experiments were performed on leaves of Populus grandidentata Michx., and $P$. tremuloides Michx. Fully developed leaves were used, and the experiments were made in midsummer. Young leaves and very old leaves of these species do not produce intumescences (La Rue, 1933a, 1933b).

In one set of experiments slices of intumescencebearing leaves, pulp of intumescences scraped from leaves, ether extract of leaves which bore great numbers of intumescences, and extract of Rhizopus suinus were anplied to the surfaces of normal leaves. On account of the necessity of keeping these leaves in a horizontal position, it was difficult to inclose them in a damp chamber with satisfactory ventilation. They were laid on water-saturated filter paper in low glass moist chambers. These chambers were opened three times daily and waved about in the air to secure a change of gases. While the air in the dishes was probably changed sufficiently to prevent the formation of intumescences, the leaves in contact with the filter paper may have formed pockets in which the gases were retained so that some intumescences were produced from this cause.

1 Received for publication May 11. 1936.

Papers from the Department of Botany of the Tniversity of Michigan No. 586, reporting work done at the University of Michigan Biological Station.
In another group of experiments ether extracts of intumescence bearing leaves, extract of Rhizopus suinus, and $\beta$-indolylacetic acid were injected into leafy twigs. Over the freshly cut end of a twig a rubber tube was slipped, which was then firmly attached by wrapping it with cord. The rubber tube was then fastened to a glass burette into which the solution to be injected was poured. The burette was attached by a short rubber tube to the outlet of an air tank in which pressure was produced by admitting water. In this way a pressure of approximately thirty pounds was applied to the solution which was forced into the twig and out into the leaves. In a short time all the leaves became injected with liquid, as their appearance clearly indicated.

The twigs which had been injected in the manner just described were placed with their cut ends in water inside gallon jars in which ventilation was secured by drawing air through them by an aspirator. The rate of passage of the air was about one liter per minute. Before entering the chambers, the air was bubbled through a train of four wash bottles containing water. Condensation on the walls of the chambers showed that the air inside was saturated with water vapor.

It should be noted that the possible effect of illuminating gas was eliminated, because no natural or artificial illuminating gas is present within several miles of the University of Michigan Biological Station, where these experiments were performed.

The ether extract was made by grinding in ether practically free from hydrogen peroxide a quantity of leaves on which intumescences had been induced by storing them in unventilated damp chambers. The ether was evaporated at a temperature of $30^{\circ} \mathrm{C}$., and the residue was taken up in a small amount of water.

The extract of Rhizopus suinus was obtained from Dr. K. V. Thimann, of the California Institute of Technology, and the $\beta$-indolylacetic acid was supplied by Dr. F. W. Went, of the same institution.

EXPERIMENTAL RESTITS. - Intumescences induced on normal leaves with pieces of intumescences.Leaves of Populus grandidentata on which thick growths of intumescences had been induced were sliced into pieces of various size and shape. The cuts were made at only a slight angle with the surfaces of the leaves so that large numbers of intumescences were cut open. These pieces were then laid against normal leaves which were kept on moist filter paper in closed damp chambers which were opened thrice daily to allow ventilation. Pieces were sliced off normal leaves without intumescences and laid on normal leaves as controls. Experimental and control leaves were kept in the same chambers. 
The normal leaves with pieces of normal leaves against them developed numerous intumescences, probably because the spaces between the leaves then became little closed chambers similar to those in which intumescences regularly develop. The leaves which had the sliced intumescences against them, however, developed several times as many of the outgrowths as the controls. In many cases the applied pieces of intumescence-bearing leaf were outlined by surrounding rings of intumescences, indicating strongly that some intumescence-forming stimulus had been transferred from the cut pieces to the normal leaves.

Intumescences produced on normal leaves by the application of crushed intumescences. - Leaves of Populus grandidentata which had developed a thick layer of intumescences were scraped to remove the intumescences. The crushed intumescences were then spread on halves or quarters of normal leaves which were laid on moist paper in damp chambers ventilated in the usual manner. Control leaves with no treatment were put in the same damp chambers.

The halves or quarters of leaves which had been covered with crushed intumescences developed great numbers of outgrowths, which in some cases formed a solid mass of intumescences on the treated surfaces. The untreated portions of the leaves had few, if any, intumescences. The control leaves with no treatment produced no outgrowths.

In another experiment intumescences were scraped off leaves of Populus grandidentata on which they had been induced, and rubbed on portions of leaves exactly as in the preceding experiment. After four hours the crushed intumescences were wiped off the treated surfaces. The leaves were kept on moist paper in closed chambers and ventilated as usual.

The treated surfaces developed solid masses of intumescences. Untreated parts of leaves, as well as whole leaves that were untreated, had developed no intumescences at the time the treated surfaces were completely covered with them. Later, however, a few outgrowths developed on the control surfaces, as might be expected because of the incomplete ventilation of the chambers. There was no comparison, however, in the number of intumescences developed by the treated and untreated surfaces. It seems beyond doubt that some growth stimulus had been transferred from the crushed intumescences in the four hours of contact with the normal leaves.

After the two preceding experiments had been performed, it was suggested to the writer that pulp of crushed or ground normal leaves should have been applied to the control surfaces. A test of the effect of pulp of fresh leaves was made by applying it to the upper and lower surfaces of ten normal leaves, which were then inclosed in a damp chamber through wihch air was drawn constantly as described under Materials and Methods. At the end of six days no intumescences had appeared. Untreated leaves, kept as controls in unventilated damp chambers, produced great numbers of intumescences during this period.
Apparently the intumescence-stimulating substance, if present in normal leaves, is oxidized in the ground pulp of these leaves, the remaining amount being insufficient to produce intumescences when applied to normal leaves. The pulp of intumescences, however, appears to contain enough of the substance to allow absorption of a sufficient amount to produce intumescences on normal leaves to which it is applied.

Induction of intumescences by the application of ether extract of intumescences.-A number of leaves were laid with the upper surfaces on wet paper in damp chambers. Some of the veins were split, and drops of the ether extract described under Materials and Methods were placed on the split portions of the veins. Other drops were put on the lower epidermis between the veins. Control leaves were treated the same way except that water was substituted for the leaf extract.

Toxicity of the extract was shown by numerous areas of dead tissue in the spots where the extract was applied. The areas alongside the veins beyond the split section showed abundant intumescences. Around each group of cells killed by the extract, a ring of intumescences had developed. The areas of the experimental leaves to which the extract had not been applied had very few intumescences, and the control leaves had only a small number.

Intumescences induced by the application of extract of Rhizopus suinus.-Leaves of $P$. grandidentata were used. 'The veins were sliced through with a slanting cut or split, and drops of the Rhizopus extract were put on the wounds. The leaves were then put on moist paper in dishes which were ventilated in the manner already described. Control leaves received the same treatment except that drops of water were put on the wounds instead of the Rhizopus extract.

Intumescences developed along the wounded veins, but very few elsewhere. Some intumescences developd on control leaves, but these were probably due to the inadequacy of ventilation. 'They were not strongly developed along the veins, as were those on the experimental leaves; and their number was estimated at not more than one-tenth that on the experimental leaves.

Intumesconces induced by the injection of ether extract of intumescence-bearing leaves. - Leaves of Populus grandidentata were injected through the twigs with an ether extract of leaves on which intumescences had been developed in unventilated damp chambers. Both the method of making the extract and the mode of injection have been described under Methods and Materials. Forty leaves on ten twigs were injected. They were then placed in gallon jars through which air was drawn continually by an aspirator. The same number of twigs bearing a like number of leaves were enclosed as controls with the injected leaves. The controls were not injected with water, because repeated trials (La Rue, 1933b) had shown that the injection of water into leaves of Populus grandidentata would not induce intumescences. 
The injected leaves developed a great number of intumescences, which were especially abundant along the veins--the pathways through which the solution was carried out into the leaves. Several of the injected leaves were completely covered on both surfaces. The control leaves had fairly numerous intumescences but none at all on the upper surfaces and no special development along the veins. The outgrowths were at least ten times as numerous on the injected leaves as on the controls.

Intumescences induced on submerged leaves which had been injected with ether extract of intumescence bearing leaves.-Leafy twigs of $P$. grandidentata were injected with the ether extract described above. They were then submerged in water. Normal leaves without injection were submerged as controls. The reason for this procedure was that intumescences never develop on untreated leaves which are submerged. It now occured to the writer that it was possible that the intumescence-forming substance or substances which seemed to develop in leaves in confined atmospheres in damp chambers might be unable to develop under water. If intumescences developed on submerged leaves which had been injected with extract of intumescences, it would make this idea more plausible.

Numerous low intumescences developed on all the injected leaves, but none appeared on the control leaves.

From the preceding experiments it was plain that it was possible to extract an intumescence-producing substance or substances from mature intumescences on poplar leaves. This, of course, does not prove which plant growth hormone or combination of hormones was produced-or, in fact, that the stimulating material is hormone.

Trials with extract from Rhizopus suinus.-A sample of extract made from Rhizopus suinus was secured from Dr. K. Thimann, of the California Institute of Technology. Leaves of P.grandidentata and P.tremuloides were injected through the twigs. They were then kept in ventilated damp chambers as usual. Control leaves without injection were kept in the same chambers.

$P$. tremuloides leaves developed no intumescences, whether injected or not. Injected leaves of $P$. grandidentata produced large numbers of the outgrowths. Control leaves of the latter species developed no intumescences except for two leaves which were pressed closely against the sides of the container. Even these, however, had many less than the injected leaves.

In another trial 40 leaves on eight twigs were injected with extract of Rhizopus suinus. A like number of leaves on eight twigs were injected with distilled water. Both sets of leaves were put together into damp chambers ventilated by the passage of air drawn through them by an aspirator. In the course of the experiment low water pressure interrupted the operation of the aspirator several times so that it was impossible to tell how effective the ventilation had been.
Only two of the experimental leaves failed to produce very numerous intumescences. Two control leaves formed abundant intumescences, 10 leaves showed a small number of intumescences, and 28 had none. The leaves which had been injected with Rhizopus extract, with the exception of the two mentioned above, produced great numbers of intumescences on their upper surfaces, whereas the control leaves had none.

Intumescences induced on submerged leaves injected with extract of Rhizopus suinus. - Leaves of $P$. grandidentata were injected with extract from Rhizopus suinus and then submerged in water. Normal uninjected leaves were submerged as controls, but in separate containers so that there might be no transfer of the extract by the water.

Exceedingly abundant intumescences developed on the auxin-injected leaves while the control leaves produced none.

Trials with $\beta$-indolylacetic acid. - $\beta$-indolylacetic acid, or hetero-auxin, was secured from Dr. F. C. Went, of the California Institute of Technology. This was dissolved in water, $0.5 \mathrm{mg}$. to $100 \mathrm{cc}$., or approximately 1 part of hetero-auxin to 200,000 of water. This solution was injected by air pressure into leafy twigs of Populus grandidentata and $P$. tremuloides. Five twigs and 20 leaves of each species were used. The leafy twigs were kept in jars ventilated by drawing air through them with aspirators. Five twigs bearing 20 leaves of $P$. grandidentata and a like number of twigs and leaves of $P$. tremuloides were placed in the chambers with those which had been injected with $\beta$-indolylacetic acid. These controls were not injected with water, because it was not thought that water-injected leaves provided as good controls as uninjected ones. Numerous trials (La Rue, 1933b) have shown that the injection of water does not produce intumescences in poplar leaves. Slight indications have been noted that untreated normal leaves develop intumescences more readily than water-injected ones, and for this reason they were used as controls in this experiment.

Every part of the lower surface of every $\beta$-indolylacetic acid injected leaf of $P$. grandidentata was covered with a dense mass of intumescences. Intumescences were also numerous on the control leaves of $P$. grandidentata; but there were likewise wide areas with none, and they were scattered where they did appear-not packed together. It was impossible to doubt the great difference in numbers of intumescences on the two sets of leaves. No intumescences appeared on the upper surfaces of either the auxininjected or the control leaves.

Discussion.-In earlier papers by the author (La Rue, 1933a, 1933b) it was shown that intumescences developed on leaves of $P$.grandidentata and P.tremuloides when they were kept for a few days in unventilated damn chambers. It was shown in one of these papers (La Rue, 193.3b) that the low oxygen tension of the chambers in which the oxygen had been used in respiration was related to the production of these outgrowths, which did not appear where 
there was an abundant supply of oxygen, regardless of $\mathrm{CO}_{2}$ tension, humidity of air, water supply, or other factors. Without knowing in what way the reduction of oxygen supply could favor production or accumulation of the growth hormone, the author suspected that this substance must play a part in the formation of outgrowths which are entirely due to increased cell size.

In these experiments it has been shown that the application of intumescences to fresh leaves will induce intumescences, as will smearings of crushed intumescences. Also it has been shown that the ether extracts of intumescence-bearing leaves will induce intumescences in normal leaves when injected into them. Although these experiments do not show that the transferable substance is a growth hormone, they do give rise to a suspicion that such is the case.

The results with the injection of extract from $R h i$ zopus suinus show that this substance is capable of inducing intumescences under conditions in which they do not usually develop. The same thing is shown by the injection of $\beta$-indolylacetic acid, a result which might have been predicted since Thimann (1935b) has shown that the growth substance extracted from Rhizopus is almost certainly identical with $\beta$-indolylacetic acid.

The results are definite for Populus grandidentata and much less so for $P$. tremuloides; but the latter species is always more capricious in the matter of developing intumescences and of ten fails to do so in entirely unventilated chambers in which the former species produces them abundantly at the same time. This behavior needs further study but does not vitiate the results obtained with $P$. grandidentata.

In several of the experiments the controls showed the production of some intumescences. This was to be expected, for it is difficult to keep leaves of Populus grandidentata and $P$. tremuloides in damp chambers without inducing some outgrowths. The outgrowths cannot be induced by any known method in dry air. To be sure that the air is moist and at the same time to insure the complete ventilation of every leaf is difficult and can only be done by separating each leaf from every other one, and from any other solid surface by mechanical means. This has been done in preceding experiments (La Rue, 1933b); but in these trials, where the difference in numbers of outgrowths was so pronounced between experimental and control leaves, it has not seemed necessary to do so.

It has not yet been shown by specific tests that the ether extract of intumescence-bearing poplar leaves really does contain a plant growth hormone. But it has been shown that the plant growth hormones are capable of causing similar effects, and it seems safe to assume that they are responsible for the intumescence produced in unventilated damp chambers.

Whether the intumescences are caused by an increased formation of hormone and, if so, how the lowered oxygen tension is connected with this is not known. It may be that the condition activates the hormone which is already present (and it has been noted that old leaves, presumably low in auxin, do not form intumescences), but does not increase its formation. Avery (1935) has shown that mature tobacco leaves contain very little hormone. Again, it is possible that the condition merely localizes the growth substance in the cells which undergo growth in intumescence formation. Bonner and Thimann (1935) state that in the absence of oxygen the transport of growth substance does not take place. Bonner (1933) has shown also that the growth substance is inactive in the absence of oxygen. Intumescences do not develop on poplar leaves in the complete absence of oxygen; so it appears possible that they are produced in an atmosphere which may at least reduce the rate of transport of the growth substance without rendering it inactive.

The induction of intumescences by ethylene, acetylene, and illuminating gas, as noted by Wallace (1926), seems to be in line with the observations of Crocker, Hitcheock, and Zimmerman (1935) that ethylene produces effects much like those of the auxins. However, Michener (1935) has shown that ethylene does not act as a growth hormone when tested by Avena coleoptiles, but in some manner acts on the hormone. If this be true, then these other cases of intumescence induction may be shown finally to be due to the presence of hormones, as the author assumes for those on poplar leaves.

\section{SLM MARY}

Intumescences were induced on leaves of Populus grandidentata by applying to them pieces of leaves of the same species on which intumescences were already present.

Crushed intumescences, when spread on fresh leaves of $P$. grandidentata, produced intumescences.

Ether extracts of intumescence-bearing leaves of $P$. grandidentata, when injected into normal leaves of the same species, produced intumescences. Application of ether extracts to wounded veins or unwounded surfaces of normal leaves produced the same effect.

Extract of Rhizopus suinus produced intumescences on $P$. grandidentata leaves into which it was injected. Application of this substance to wounded and nonwounded surfaces of the leaves produced the same result.

Leaves injected with extract of intumescence-bearing leaves or with Rhizopus extract and then submerged produced abundant intumescences. Submerged leaves had never before been known to develop intumescences.

Leaves of $P$.grandidentata injected with $\beta$-indolylacetic acid developed great numbers of intumescences.

It is assumed that plant growth hormones are the cause of intumescences on leaves confined in unventilated damp chambers.

\footnotetext{
Department of Botany,
}

UNiversity of Mrchigan 
Avkry, G. S. 1935. Differential distribution of a phytohormone in the developing leaf of Nicotiana, and its relation to polarized growth. Bull. Torrey Bot. Club 62 : 313-330.

Bonver, J. 1933. The action of the plant growthormone. Jour. Gen. Physiol. 17 : 63-76.

Bonner, J., AND K. V. Thimann. 1935. Studies on the growth hormone of plants. VII. The fate of growth substance in the plant and the nature of the growth process. Jour. Gen. Physiol. 18: 649-658.

Crocker, W., A. E. Hitchcock, and P. W. Zimmerman. 1935. Similarities in the effects of ethylene and the plant auxins. Contrib. Boyce Thompson Inst. 7: 231-248.

LA Rue, C. D. 1933a. Intumescences on poplar leaves. I. Structure and development. Amer. Jour. Bot. 20: $1-17$. 1933b. Intumescences on poplar leaves. II. Physiological considerations. Amer. Jour. Bot. 20: 159-175.

- 1933c. Intumescences on leaves of Eucalyptus cornuta, E. coccifera, Hieracium venosum, Mitchella repens, and Thurberia thespesioides. Phytopath. 23: 281-289.

Michener, H. D. 1935. Effects of ethylene on plant growth hormone. Science 82: 551-552.

Thimans, K. V. 1935a. Growth substances in plants. Ann. Rev. Biochem. 4: 545-568.

- 1935b. On the plant growth hormone produced by Rhizopus suinus. Jour. Biol. Chem. 109: 279-291.

Wallace, R. H, 1926. The production of intumescences upon apple twigs by ethylene gas. Bull. Torrey Bot. Club 53: 385-401.

WeNT, F. W. 1935. Auxin, the plant growth-hormone. Bot. Rev. 1: 162-182.

\section{AN UPPER CRETACEOUS WOOD: TORREYA ANTIQUA '}

\section{Irwin Boeshore and William D. Gray}

The fossil wood here described was collected from the Upper Cretaceous of Black Creek Age near Fayetteville, North Carolina, by Mr. John Rankin. The original specimen was a fragment of secondary wood measuring one foot long, two inches wide, and one inch thick. It is in a fair state of preservation but with non-uniform infiltration of mineral substances, showing regions of a white hyaline substance and other regions of a soft, brown-colored substance (fig. 1). The wood is without fusiform rays, tracheae, wood parenchyma, or resin passages of any kind; it consists wholly of pitted tracheids with conspicuous spiral thickenings. The latter feature and the absence of tracheids in wood rays are the chief diagnostic characters which ally it promptly with the genus Torreya (Tumion of Rafinesque).

Since spiral thickenings also occur on the tracheid walls of the secondary wood of Pseudotsuga, Taxus, Larix americana, and Pinus taeda, additional evidence as to the identity of our specimen is presented. The presence of well developed spirals on the tracheid walls of the entire growth ring in Torreya and Taxus is a constant and typical feature, while in Pseudotsuga, Larix, and Pinus the spirals occur in more or less isolated regions and may be imperfectly developed. Furthermore, the resinous containers are absent from Torreya and Taxus, but present in Pseudotsuga, Larix, and Pinus. The well developed spirals in the fossil wood and the absence therefrom of resinous containers exclude it from the last three genera. The main choice for its position then lies between Torreya and Taxus. The structure of our specimen conforms more to the wood structure of Torreya in the large, chiefly squarish, tracheids with rather open spirals in $2-4$ series, and in the oval or

1 Received for publication May 15, 1936. oblong ray cells in tangential view, than to that of Taxus with its small, chiefly rounded, tracheids with rather close spirals in 2 (rarely 3 ) series, and the narrowly oblong ray cells in tangential view.

A consideration of the distribution of the present day representatives of Torreya reveals that the four living species comprising the genus are confined to more or less localized areas which are widey separated from each other. The two American species are separated by the breadth of the entire continent; T. taxifolia, the Florida Stinking Cedar, being found on the ridges which extend into the Apalachicola River swamps, while $T$. californica, the California Nutmeg, is found in the Santa Cruz and Sierra Nevada mountains. The two other living species of Torreya are Asiatic; $T$. nucifera being found in the mountains of Japan, and T. grandis occurring in the mountains of northern China. In addition to the four species just listed, a fifth, T. Fargesii, has also been described; this species, however, is little known and is considered by some to be merely a variety of T. grandis.

Historical. - There have been many reports of the occurrence of fossil representatives of Torreya; the species generally being described on the basis of leafy branches or seeds. Such reports are from widely separated locations and indicate that the distribution of the genus in past geological times was much wider than the distribution of the living species. Berry (1908) pointed out that Torreya is not strictly speaking a member of the existing flora but rather a relic of a prehistoric one; furthermore, he predicted that only a few centuries will elapse until the genus will be extinct. This prediction was more or less refuted by Sellards (1914), who stated that $T$. taxifolia is in no danger of becoming extinct and among Florida trees now ranks seventh in abundance. 